\title{
APROVEITAMENTO BIOTECNOLÓGICO DE SORO E PERMEADO DE SORO DE QUEIJO PARA A PRODUÇÃO DE ETANOL POR SACCHAROMYCES CEREVISIAE
}

\author{
S. GABARDO ${ }^{1}$, G. F. PEREIRA ${ }^{1}$, M. P. KLEIN ${ }^{2}$, P.F. HERTZ ${ }^{2}$, R. RECH ${ }^{2}$, M.A.Z. AYUB ${ }^{1,2}$
}

${ }^{1}$ Universidade Federal do Rio Grande do Sul, Laboratório de Biotecnologia e Engenharia Bioquímica

${ }^{2}$ Universidade Federal do Rio Grande do Sul, Instituto de Ciências e Tecnologias de Alimentos E-mail para contato: sabrinagabardo@gmail.com

RESUMO - O desenvolvimento de pesquisas para a produção de biocombustíveis alternativos tem sido significativo nos últimos anos, entre as quais pode-se citar a utilização de substratos alternativos e de baixo custo para a produção de etanol. O presente trabalho avaliou a utilização de soro e permeado de soro de queijo para a produção de etanol, utilizando a levedura Saccharomyces cerevisiae PE-2. O soro e o permeado de soro foram tratados enzimaticamente para a hidrólise da lactose e utilizados como meio de cultivo sem suplementação. Os cultivos foram realizados em incubadora rotatória a $30^{\circ} \mathrm{C}, 150 \mathrm{rpm}$ por $48 \mathrm{~h}$. A glicose foi prontamente metabolizada em ambos os meios de cultivo, enquanto que a galactose foi metabolizada de forma mais lenta em permeado de soro. A eficiência de conversão variou entre $75,4 \%$ e $81,1 \%$ e a produtividade volumétrica variou entre $0,34 \mathrm{~g} \mathrm{~L}^{-1} \mathrm{~h}^{-1}$ e $0,40 \mathrm{~g} \mathrm{~L}^{-1} \mathrm{~h}^{-1}$, sendo a concentração máxima de etanol de $19,0 \mathrm{~g} \mathrm{~L}^{-1}$.

\section{INTRODUÇÃO}

O aperfeiçoamento de processos fermentativos associados à crescente preocupação ambiental tem impulsionado pesquisas no sentido de desenvolver tecnologias alternativas de geração de energia (Canacki e Sanli, 2008). O aproveitamento de subprodutos industriais para a produção de etanol tem sido significativo nos últimos anos devido ao mercado crescente e a potencial redução dos custos de produção associada a sua utilização. O emprego de substratos alternativos e de baixo custo, tais como o permeado e o soro de queijo, além de auxiliar na produção de etanol, pode, ainda, minimizar problemas ambientais através de seu aproveitamento neste bioprocesso (Gabardo et al., 2012).

O soro de queijo, subproduto da indústria de laticínios, se caracteriza por ser rico em nutrientes, contendo apreciáveis quantidades de lactose $\left(45-50 \mathrm{~g} \mathrm{~L}^{-1}\right)$, proteínas $\left(6-8 \mathrm{~g} \mathrm{~L}^{-1}\right)$, e sais minerais $(8-10 \%$ do extrato seco). Processos que valorizam o soro de queijo estão sendo 
constantemente realizados, entre os quais, a recuperação das proteínas através do processo de separação por ultrafiltração, o qual gera grandes volumes remanescentes de lactose, também denominado de permeado. Este produto, o permeado, assim como o soro de queijo, continua sendo um poluente importante visto que retêm mais de $70 \%$ dos sólidos totais presentes no soro de queijo. Dessa forma, o permeado apresenta problemas de disposição, tanto em termos de volume produzidos quanto de carga orgânica, aproximadamente igual ao do soro de queijo (Siso, 1996; Domingues et al., 2001; Guimarães et al., 2010). Caracterizado por elevados valores de demanda bioquímica de oxigênio (30-50 $\mathrm{g} \mathrm{L}^{-1}$ ), o soro de queijo apresenta potencial poluidor aproximadamente 100 vezes maior que o esgoto doméstico (Siso, 1996; Guimarães et al., 2010). Sendo a quantidade de lactose disponível no mundo para a produção de etanol maior que 4 milhões de toneladas por ano, é sugestivo o grande potencial de aproveitamento desta fonte de carbono alternativa para a condução deste bioprocesso (Guimarães et al., 2010).

A produção mundial de etanol foi de aproximadamente 65 bilhões de litros no ano de 2008, sendo o continente Americano responsável por $70 \%$ dessa produção. O maior produtor mundial são os Estados Unidos, produzindo no ano de 2008 cerca de 34,0 bilhões de litros. Em segundo lugar encontra-se o Brasil, chegando a uma produção de 25,7 bilhões de litros no ano de 2010, contribuindo de forma significativa no cenário internacional (Demirbas, 2007; Guimarães et al., 2010; Mussato et al., 2010). Com a perspectiva de crescimento da demanda de álcool combustível, tecnologias capazes de melhorar o desempenho do processo ganham importância fundamental no Brasil e no mundo. Leveduras tradicionalmente utilizadas em plantas industriais do Brasil, como as do gênero de Saccharomyces cerevisiae, reconhecidas pela tolerância a altas concentrações de etanol e de açúcar, não são capazes de utilizar a lactose como fonte de energia. Contudo, estas linhagens são capazes de metabolizar a glicose e a galactose, monômeros constituintes da lactose. Neste sentido, o presente trabalho teve como objetivo avaliar a produção de etanol por Saccharomyces cerevisiae PE-2 em meio soro e permeado de soro de queijo previamente hidrolisados com $\beta$-galactosidase e comparar a capacidade de bioconversão nos diferentes meios de cultivo.

\section{MATERIAIS E MÉTODOS}

\subsection{Permeado e soro de queijo}

O permeado de soro de queijo em pó foi fornecido pela Sooro (PR, Brasil) e o soro de queijo em pó fornecido pela Elegê Laticínios S.A. (RS, Brasil). Para sua preservação, ambos permaneceram estocados em freezer a $-16^{\circ} \mathrm{C}$. 


\section{9 a 22 de outubro de 2014 \\ Florianópolis/SC}

\subsection{Microrganismo e manutenção celular}

A levedura Saccharomyces cerevisiae PE-2 foi cedida pelo Departamento de Genética do Centro de Ciências Biológicas da Universidade Federal de Pernambuco. A linhagem foi mantida em placas de Petri contendo meio nutritivo YEPD, composto de extrato de levedura $\left(10 \mathrm{~g} \mathrm{~L}^{-1}\right)$, peptona bacteriológica $\left(20 \mathrm{~g} \mathrm{~L}^{-1}\right)$, glicose $\left(20 \mathrm{~g} \mathrm{~L}^{-1}\right)$, e ágar $\left(20 \mathrm{~g} \mathrm{~L}^{-1}\right), \mathrm{pH}$ ajustado para 7,0 com solução de $\mathrm{NaOH}$ 0,1 M. Previamente a sua utilização, o meio de cultivo foi esterilizado em autoclave a $121{ }^{\circ} \mathrm{C}$ por $15 \mathrm{~min}$. A linhagem foi plaqueada em meio YEPD, e incubada em estufa a $30{ }^{\circ} \mathrm{C}$ por $48 \mathrm{~h}$ para o crescimento celular e, posteriormente armazenada a $4{ }^{\circ} \mathrm{C}$. A cada 30 dias as culturas foram renovadas via repique.

\subsection{Fermentação em frascos agitados}

O pré-inóculo foi preparado através da transferência asséptica de uma colônia isolada para $50 \mathrm{~mL}$ de meio YEPD (extrato de levedura, $10 \mathrm{~g} \mathrm{~L}^{-1}$; peptona bacteriológica, $20 \mathrm{~g} \mathrm{~L}^{-1}$ e glicose, $\left.20 \mathrm{~g} \mathrm{~L}^{-1}, \mathrm{pH} 7,0\right) \mathrm{em}$ frascos cônicos de $250 \mathrm{~mL}$. A linhagem foi incubada em agitador rotacional, sob agitação orbital de $180 \mathrm{rpm}$, a uma temperatura de $30{ }^{\circ} \mathrm{C}\left( \pm 0,2{ }^{\circ} \mathrm{C}\right)$, por $12 \mathrm{~h}$. Os inóculos foram preparados através da padronização da concentração celular para densidade ótica a $600 \mathrm{~nm}$ $\left(D O_{600}\right)$ igual a 1 . Os meios soro e permeado de soro foram previamente hidrolisados com $\beta$ galactosidase comercial utilizando um volume de enzima de $0,5 \mathrm{~mL} \mathrm{~L}^{-1}$, a temperatura ambiente, em $\mathrm{pH} 7,0$, por $8 \mathrm{~h}$ e sob branda agitação. O cultivo foi conduzido em frascos cônicos de $250 \mathrm{~mL}$ contendo $144 \mathrm{~mL}$ de meio de fermentação esterilizado $\left(121{ }^{\circ} \mathrm{C}, 15 \mathrm{~min}\right), \mathrm{pH} 7,0$ e $16 \mathrm{~mL}$ de inóculo, totalizando um volume de fermentação de $160 \mathrm{~mL}$. Para evitar a precipitação das proteínas durante o processo de esterilização, o soro de queijo foi previamente hidrolisado com uma protease comercial a $55^{\circ} \mathrm{C}, \mathrm{pH} 8,5$ por $3 \mathrm{~h}$. Os frascos cônicos contendo as culturas foram incubados em agitador orbital, a uma temperatura de $30^{\circ} \mathrm{C}\left( \pm 0,2^{\circ} \mathrm{C}\right)$, sob agitação de $150 \mathrm{rpm}$ por $48 \mathrm{~h}$.

\subsection{Métodos analíticos}

Amostras de $3 \mathrm{~mL}$ do meio fermentativo foram coletadas em 0 h, 6 h, 12 h, $24 \mathrm{~h}$ e $48 \mathrm{~h}$ de cultivo para determinação da concentração de glicose, galactose e etanol. O preparo das amostras foi realizado através da centrifugação a $3000 \times \mathrm{g}$ por $15 \mathrm{~min}, 4^{\circ} \mathrm{C}$ (Brinkmann Instruments Inc., Eppendorf Bench Centrifuge, modelo 5410, Alemanha) para separar as células do meio de cultivo e o sobrenadante foi analisado. As concentrações dos açúcares e de etanol foram analisadas através de cromatografia líquida de alta eficiência (CLAE) (Shimadzu) utilizando detector de índice de refração (IR) e coluna Bio-Rad Aminex HPX $87 \mathrm{H}$, a $45^{\circ} \mathrm{C}$, utilizando solução de ácido 
sulfúrico $5 \mathrm{mM}\left(\mathrm{H}_{2} \mathrm{SO}_{4}\right)$ como fase móvel na vazão de $0,6 \mathrm{~mL} \mathrm{~min}^{-1}$, e $20 \mu \mathrm{L}$ de volume de amostra.

\section{RESULTADOS E DISCUSSÃO}

A linhagem de $S$. cerevisiae PE-2 é convencionalmente utilizada em plantas industriais de etanol do Brasil devido a suas características fisiológicas como, por exemplo, a tolerância a altas concentrações de etanol e altos rendimentos obtidos a partir da cana de açúcar e melaço (Basso et al., 2008). Contudo, esta linhagem não tem sido explorada para a bioconversão em etanol a partir de soro e permeado de soro de queijo. O gênero de Saccharomyces cerevisiae se caracteriza por não assimilar diretamente a lactose devido a ausência dos genes $L A C 12$ e $L A C 4$, os quais codificam as enzimas, lactose-permease e $\beta$-galactosidase, respectivamente. Contudo, se a lactose for hidrolisada em seus monossacarídeos, glicose e galactose, através da ação da enzima $\beta$ galactosidade, estes podem ser metabolizados e convertidos a etanol pelas vias glicolítica e de Leloir (Rubio-Teixeira, 2005; Timson, 2007; Bai et al., 2008; Silva et al., 2010).

A cinética do consumo dos monossacarídeos glicose e galactose e da produção de etanol em meio soro e permeado de soro de queijo pode ser observada na Figura 1. Um comportamento diauxico é observado para ambos os meios de cultivo, em que a glicose é consumida primeiramente à galactose. Este fato é característico de linhagens de $S$. cerevisiae e acontece devido à repressão catabólica dos genes GAL pela glicose (Guimaraes et al., 2010). Além do mais, a galactose foi metabolizada mais lentamente do que a glicose, levando mais que o dobro do tempo para a sua exaustão. Isto pode ser explicado devido ao fato de que a bioconversão da galactose exige energia e etapas catabólicas adicionais, uma vez que a galactose deve primeiramente entrar na via Leloir, transformando-se em um intermediário glicolítico, para posteriormente entrar na via glicolítica e finalmente ser reduzida a etanol (Rubio-Texeira, 2005; Timson, 2007). Além disso, a metabolização da galactose diferiu nos distintos meios. Uma explicação para isso é devido ao meio soro de queijo ser mais rico em nutrientes, contendo maiores quantidades de proteínas e sais minerais, favorecendo o crescimento celular e a produção de etanol. Neste mesmo sentido, a cinética de produção de etanol foi mais rápida em meio soro de queijo do que em permeado de soro de queijo nas primeiras $24 \mathrm{~h}$, contudo para o período de $48 \mathrm{~h}$, a produção de etanol foi maior em permeado de soro de queijo (19 $\left.\mathrm{g} \mathrm{L}^{-1}\right)$, o que refletiu em maiores produtividades volumétricas (Tabela 1). Isto se deve pela diferença inicial dos açúcares, em que no início do experimento a concentração de glicose e galactose ficou em $20 \mathrm{~g} \mathrm{~L}^{-1}$ ao passo que em permeado de soro a concentração inicial foi de $25 \mathrm{~g} \mathrm{~L}^{-1}$. O fator de conversão de açúcares a etanol foi maior em meio soro de queijo, sugerindo uma maior adaptação em meio soro de queijo pela levedura. 

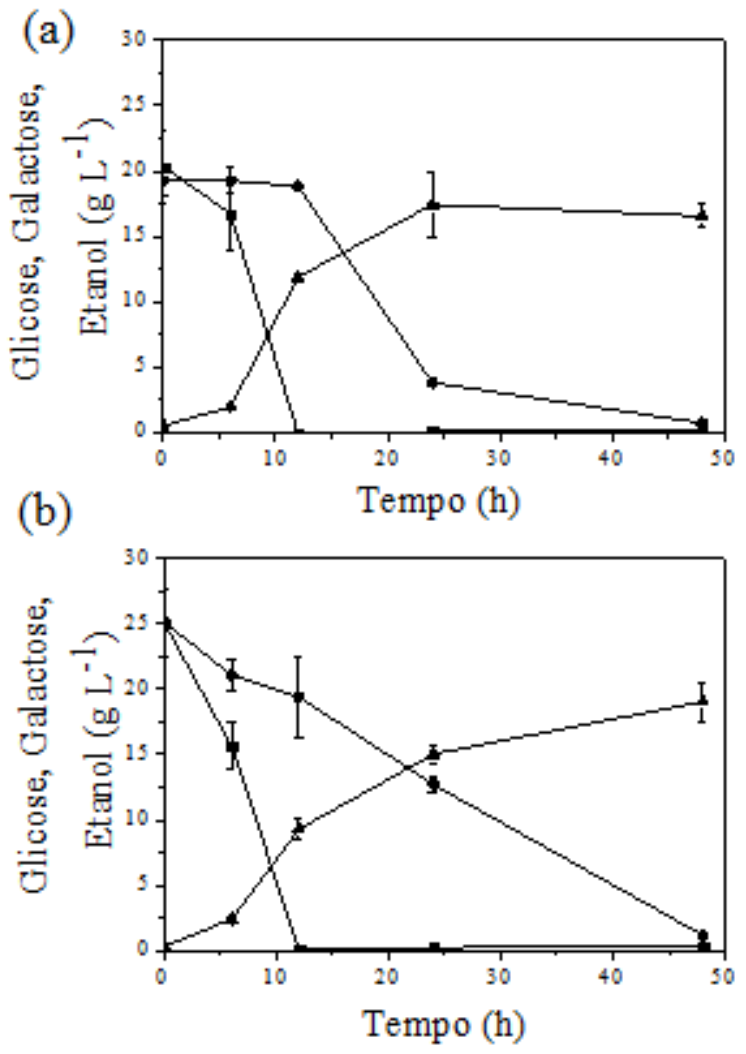

Figura 1. Cinética do consumo de glicose e galactose e produção de etanol por Saccharomyces cerevisiae PE-2 em meio soro de queijo (a) e em permeado de soro de

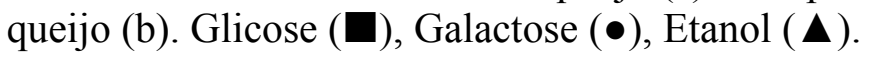

Tabela 1. Fator de conversão de substrato a etanol $\left(Y_{P / S}\right)$, eficiência de conversão $(\eta)$ e produtividade volumétrica de etanol $\left(Q_{P}\right)$ nos meios soro de queijo e permeado de soro de queijo previamente hidrolisados $\operatorname{com} \beta$-galactosidade.

\begin{tabular}{lccc}
\hline \multicolumn{1}{c}{ Meio de fermentação } & $\boldsymbol{Y}_{\boldsymbol{P} / \boldsymbol{S}}\left(\mathbf{g ~ g ~}^{\mathbf{- 1}}\right)$ & $\boldsymbol{\eta} \mathbf{( \% )}$ & $\boldsymbol{Q}_{\boldsymbol{P}}\left(\mathbf{g ~ L ~}^{-\mathbf{1}} \mathbf{h}^{\mathbf{- 1}}\right)$ \\
\hline Soro de queijo & 0,41 & 81,1 & 0,34 \\
Permeado de soro de queijo & 0,38 & 75,4 & 0,40 \\
\hline
\end{tabular}

Os parâmetros cinéticos obtidos neste trabalho foram ligeiramente inferiores aos reportados em literatura, contudo, é válido enfatizar que estes últimos utilizaram $S$. cerevisiae geneticamente modificada, o que pode influenciar nas características fisiológicas e no metabolismo do carbono. Por exemplo, Silva et al. (2010) obtiveram uma produtividade volumétrica de $0,74 \mathrm{~g} \mathrm{~L}^{-1} \mathrm{~h}^{-1} \mathrm{e}$ uma conversão teórica de $76 \%$ partir de soro de queijo deproteinizado, utilizando $S$. cerevisiae recombinate, NCYC869-A3/T1-E, a uma temperatura de $30{ }^{\circ} \mathrm{C}$ e $150 \mathrm{rpm}$; além disso, alto fator 
de conversão $\left(0,48 \mathrm{~g} \mathrm{~g}^{-1}\right)$ foi alcançado por $S$. cerevisiae geneticamente modificada (GRF167) a partir de meio sintético contendo $20 \mathrm{~g} \mathrm{~L}^{-1}$ de glicose e de galactose (Ramakrishnan e Hartley, 1993). Valores similares aos obtidos no presente trabalho foram observados por Domingues et al. (1999) ao utilizar $S$. cerevisiae geneticamente modificada (linhagem T1), chegando a uma produtividade volumétrica de $0,40 \mathrm{~g} \mathrm{~L}^{-1} \mathrm{~h}^{-1}$ e uma eficiência de $60 \%$ a partir de meio sintético contendo lactose como fonte de carbono.

No presente trabalho, fica evidenciada a capacidade de bioconversão do soro e permeado de soro por $S$. cerevisiae PE-2, uma levedura convencionalmente empregada em plantas industriais, o que permite testar posteriormente condições mais aproximadas das condições industriais. A utilização do soro e permeado de soro de queijo como fonte alternativa de carbono em processos fermentativos, consiste em uma proposta bastante interessante, podendo minimizar o seu potencial poluidor, além de tornar a produção de etanol um processo menos oneroso e potencialmente competitivo economicamente.

\section{REFERÊNCIAS}

BAI, F.W;ANDERSON, W.A; MOO-YOUNG, M. Ethanol fermentation technologies from sugar and starch feedstocks. Biotechnol. Adv., v. 14, p. 89-105, 2008

BASSO, L. C.; de AMORIM, H. V.; de OLIVEIRA, A.J., et al. Yeast selection for fuel ethanol production in Brazil. FEMS Yeast Research, v. 8, p.1155-1163, 2008.

CANAKCI, M.; SANLI, H. Biodiesel production from various feedstocks and their efects on the fuel properties. J. Ind.Microbiol. Biotechnol., v. 35, p. 431-441, 2008.

DEMIRBAS, A. Progress and recent trends in biofuels. Progress Energy Combustion Sci., v. 33, p. 1-18, 2007.

DOMINGUES, L; TEIXEIRA, J.A; LIMA, N. Construction of a flocculent Saccharomyces cerevisiae fermenting lactose. Appl. Microbiol.Biotechnol., v.51, p.621-626, 1999.

DOMINGUES, L; LIMA, N; TEIXEIRA, J.A. Alcohol production from cheese whey permeate using genetically modified flocculent yeast cells. Biotechnol. Bioeng., v. 72, p. 507-514, 2001.

GABARDO, S.; RECH, R.; AYUB, M. A. Z. Performance of different immobilized-cell systems to efficiently produce ethanol from whey: fluidized batch, packed-bed and fluidized continuous bioreactors. J. Chem. Technol.Biotechnol., v. 87, p.1194-1201, 2012. 
GUIMARÃES, P.M.R; TEIXEIRA, J.A; DOMINGUES, L. Fermentation of lactose to bioethanol by yeasts as part of integrated solutions for the valorization of cheese whey. Biotechnol. Adv., v.28, p. 375-384, 2010.

MUSSATTO S. I.; DRAGONE G.; GUIMARAES P.M.R., et al. Technological trends, global market, and challenges of bio-ethanol production. Biotechnol. Adv., v.28, p.817-830, 2010.

RAMAKRISHNAN, S; HARTLEY, B.S. Fermentation of lactose by yeast cells secreting recombinant fungal lactase. Appl. Environmental Microbiol., v. 59, p.4230-4235, 1993.

RUBIO-TEXEIRA, M. A comparative analysis of the genetic switch between not-so-distant cousins: Saccharomyces cerevisiae versus Kluyveromyces marxianus. FEMS Yeast Research, v. 5, p. 1115-1128, 2005.

SILVA, A., GUIMARES, P.M.R., TEIXEIRA, J.A., DOMINGUES, L. Fermentation of deproteinized cheese whey powder solutions to ethanol by engineered Saccharomyces cerevisiae: effect of supplementation with corn steep liquor and repeated-batch operation with biomass recycling by flocculation. J. Ind. Microbiol.Biotechnol., v. 37, p. 973-982, 2010.

SISO M. I. G. The biotechnological utilization of cheese whey: a review. Bioresource Technol., v. 57, p. 1-11, 1996.

TIMSON, D. J. Galactose metabolism in Saccharomyces cerevisiae. Dynamic Biochem., Process Biotechnol. Molecular Biology. In: Global Sci. Books, v.1, p.63-73, 2007. 